\title{
Optimal Placement of FACTs Devices in Iraqi National Super Grid System (INSGS) Using HLSI
}

\author{
Rashid H. AL-Rubayi ${ }^{1}$, Luay G. Ibrahim ${ }^{\text {* }}$ \\ ${ }^{l}$ Department of Electrical Engineering, University of Technology, Baghdad, Iraq \\ *Email:Luay_g@yahoo.com
}

\begin{abstract}
The numerous power system blackouts in the past decade and in recent times attest to the fact that more works still needs to be done to tackle the problem of voltage instability and the resultant voltage collapse. This study presents a method to find and select the optimum location of FACTs device using the hybrid line stability index (HLSI) that is appropriate for the prediction voltage collapse in power system networks. Such the HLSI was obtained by deriving expressions basics equivalent Line Stability Index (LSI), and Fast Voltage Stability Index (FVSI) and mix theirs through a switch logic based on the voltage angle difference Where indicate the nearness voltage collapse. The HLSI has tested in Iraqi National Super Grid System (INSGS) it gives the same results as the other indicators (LSI \& FVSI). For the base state, INSGS was found to be stable with all the three indicators have approximately equal values least than 1 for all lines. The contingency state detects that ranks of bus 24 the weakest bus in the system with the lower maximum allowable reactive load of (490.371 Mvar) and the line critical concerning bus 24 , the line connecting bus 20 to bus 24 . The values the three indicators, LSI, FVSI, and HSLI, approximately equal, increasing the accuracy of HLSI. All simulations are carried out in MATLAB R2014a software.
\end{abstract}

Indexed Terms- FACTs, FVSI, HLSI, INSGS, LSI.

\section{INTRODUCTION}

During the last years, numbers of new generation stations have been installed in the Iraqi National Super Grid System (INSGS). Shortly, there are new projects for installing new generation units, which will cause the generation capacity to rise at the expense of the transmission line capacity. This may lead to some transmission lines reaching their thermal limits and may increase the probability of the system facing low-frequency oscillations, which may cause instability $[1,2]$.

The number of interruptions in the system over the past decade has been evidence of the way that all the more should be done to address the instability of the voltages and the ensuing collapse. The power system is foreseeable remain in equilibrium under normal conditions and requires that it respond to the restoration of the system state to agreeable conditions after a disturbance, i.e., voltage after the disturbance repaired to value close to the pre-disturbance state. Voltage instability occurs in the power system when a disturbance in the network leads to a gradual and uncontrollable reduction the voltage [3].

Difficulties such as line disruptions because of faults, external factors, and an unusual increase in load or incorrect running of voltage control devices are causes of voltage instability. The inability of the system to fit the requirements of reactive power can also lead to voltage instability. If no measures are taken to confirm this voltage instability, it results in a decrease in system voltage and thus voltage breakdown resulting in a partial or total blackout of system. All these things scare essential service to produce reliable and stable in the power supply for consumers $[4,5]$. 
Voltage stability is said to be the ability of a power system to maintain acceptable voltages at all network buses of the system under normal operating conditions and after being subjected to a disturbance [6,7]. A modal analysis of the Voltage Stability has been introduced by [8,9] with determine the placement of FACTS based on participation parameter. This paper proposes HLSI that is suitable for the prediction of voltage collapse in INSGS. The study will also identify the weak bus and critical lines in order to determine the optimum location of FACTS device in the INSGS.

\section{MATERIALS AND METHOD}

The Voltage stability, to a large degree, have to do with transmission line parameters and system load parameters, which show how close each transmission line is to voltage instability, which has become gradually a main tool for assessing and controlling voltage stability by power system operators. This indices use for online or offline monitoring of the power system in seek to prophesy nearness to voltage instability or collapse. In this paper, propose the new HLSI for power system networks to monitor voltage stability state and/or for voltage collapse prediction. To derive the mathematical formulation for HLSI, we first derive, Line Stability Index (LSI) [10] and the Fast Voltage Stability Index (FVSI) [11] and mix them based on a seeing that the FVSI is an approximation of the LSI under voltage angle conditions so that the HLSI takes advantages of improved prediction rigor and speed. The single line diagram of two buses had shown Figure 1. The all parameters and variables are in per unit.

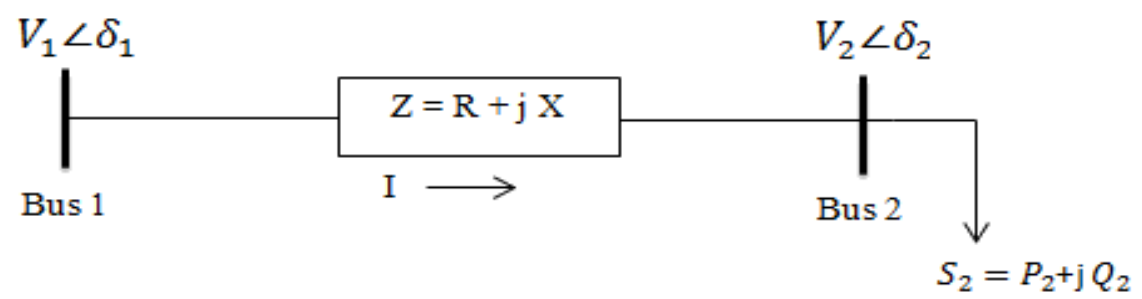

Figure 1: Single line diagram of two buses

Can be defined the power flowing at Bus 2 below:

$$
S_{2}=P_{2}+j Q_{2}
$$

$S_{2}=V_{2} I_{2}{ }^{*}$

Where

$$
\overline{I_{2}}=\frac{\bar{V}}{\bar{Z}}=\frac{V_{1} \angle \delta_{1}-V_{2} \angle \delta_{2}}{Z \angle \theta}
$$

Therefore,

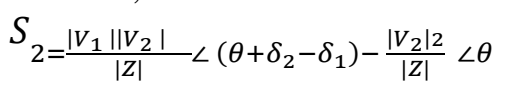

The phasor diagram for the two-bus transmission system of Figure 1 with I as the reference phasor is as shown in Figure 2. 


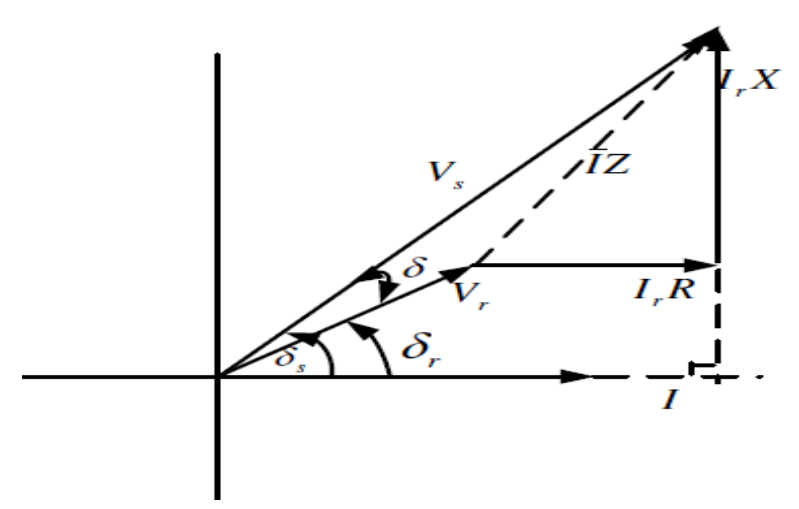

Figure 2: Phasor diagram of two-bus transmission line

Expressing $S_{r}$ in describe of its real and imaginary parts, equation (4) becomes:

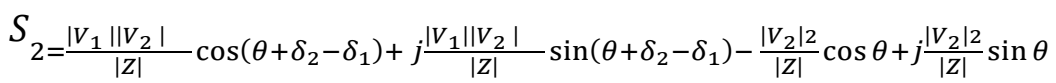

Rearrange equation (5) gives

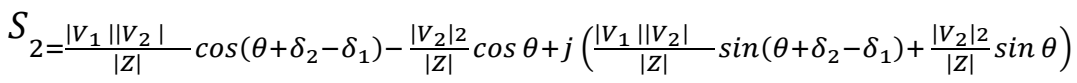

Then comparing parts on both sides real and imaginary, gives

$$
\begin{aligned}
& P_{2=}=\frac{\left|V_{1}\right|\left|V_{2}\right|}{|Z|} \cos \left(\theta-\delta_{1}+\delta_{2}\right)-\frac{\left|V_{2}\right| 2}{|Z|} \cos \theta \\
& Q_{2=}=\frac{\left|V_{1}\right|\left|V_{2}\right|}{|Z|} \sin \left(\theta-\delta_{1}+\delta_{2}\right)+\frac{\left|V_{2}\right| 2}{|Z|} \sin \theta
\end{aligned}
$$

Substituting $\delta=\delta_{2}-\delta_{1}$ and finding roots equation in terms of $Q_{2}$ in (8) gives

$$
\frac{\left|V_{2}\right| 2}{|Z|} \sin \theta-\frac{\left|V_{1} \| V_{2}\right|}{|Z|} \sin (\theta-\delta)+Q_{2}=0
$$

Therefore, quadratic equation voltage shows as follows:

$$
\frac{\sin \theta}{|Z|} V_{2}^{2}-\left|V_{2}\right| \frac{\left|V_{1}\right| \sin (\theta-\delta)}{|Z|}+Q_{2}=0
$$

Then by solving $\mathrm{V}_{2}$ gives:

$$
V_{2}=\frac{\frac{\left|V_{1}\right| \sin (\theta-\delta)}{|Z|} \pm \sqrt{\left(\frac{\left(V_{1} \mid \sin (\theta-\delta)\right)}{|Z|}\right)^{2}-4 \frac{\sin \theta}{|Z|} Q_{2}}}{2 \frac{\sin \theta}{|Z|}}
$$

Discriminant of equation (11) must be larger than or equal to zero, for the stability.

$$
\frac{\left(\left|V_{1}\right|^{2} \sin ^{2}(\theta-\delta)\right)}{|Z|^{2}}-4 \frac{\sin \theta}{|Z|} Q_{2} \geq 0
$$

Multiply both sides with $|Z|^{2}$, we have

$$
\left|V_{1}\right|^{2} \sin ^{2}(\theta-\delta)-4|Z| \sin \theta Q_{2} \geq 0
$$

However, $\mathrm{X}=|Z| \sin \theta$, from relevance impedance triangle show as follows: 
Replace $\mathrm{X}$ in to (13), then

$$
V_{1}^{2} \sin ^{2}(\theta-\delta)-4 X Q_{2} \geq 0
$$

Divided both sides by $\left|V_{1}\right|^{2} \sin ^{2}\left(\theta_{-} \delta\right)$, thereafter equation (14) becomes

$$
1-\frac{4 X Q_{2}}{V_{1}^{2} \sin ^{2}(\theta-\delta)} \geq 0
$$

Then, (LSI) is obtained as:

$$
L S I=\frac{4 X Q_{2}}{\left|V_{1}\right|^{2} \sin ^{2}(\theta-\delta)} \leq 1
$$

Equation (16) when $\delta \approx 0$ can be inferred that:

$$
\frac{4 X Q_{2}}{\left|V_{1}\right|^{2}(\sin \theta)^{2}} \leq 1
$$

The power triangle that $\mathrm{X}=|Z| \sin \theta$ which suggests:

$$
\sin \theta=\frac{X}{|Z|}
$$

Replacing equation (18) into equation (17) and simplify yields term for voltage stability with $\delta$ negligibly small:

$$
F V S I=\frac{4 Q_{2}(|Z|)^{2}}{\left|V_{1}\right|^{2} X} \leq 1
$$

Therefore, we suggest mix equations (16) \& (19) equation single to calculate nearness the voltage collapse according to the conversion function $\mu$, shown equation (20). Computed $\delta$ in the load- flow program at each against the threshold value, $\delta \mathrm{c}$, is tested in order to find whether $\mu$ is $(1,0)$. For a hybrid stability indicator, it obtains stability and accuracy with better stability.

$$
H L S I=\frac{4 Q_{2}}{\left|V_{1}\right|^{2}}\left[\frac{(|Z|)^{2}}{X} \mu-\frac{x}{\sin ^{2}(\theta-\delta)}(\mu-1)\right] \leq 1 \quad \mu= \begin{cases}1 & \delta<\delta_{c} \\ 0 & \delta \geq \delta_{c}\end{cases}
$$

$" \mu$ " is a function which value conversion depends on if the difference angle $\delta$ very small or not. The large voltage angle difference between the two loading buses indicates on that a power system loaded or There is increased resistance between bus loading. then, the voltage angle difference, delta ' $\delta$ ' cannot be ignored exactly as it did in the mathematical formulation of FVSI. When the HLSI is less than 1, the system is static. The nearer the value of (1), the system was unstable, and the near voltage collapsed.

Prediction of the voltage collapse is summarizing in the determination of the maximum load-ability, identification of the weakest bus for the network and the critical line with respect to load buses. This information is useful optimally locate possible points of placement of FACTs devices to combat voltage collapse in power system networks. The following algorithm steps are followed in determining the maximum load-ability and weak bus identification:

1. Input the bus and the line data for the Iraqi National Super Grid System (INSGS).

2. The Power flow solution program is run for the base case using the Newton- Raphson method in the MATLAB environment.

3. The line stability indices' (LSI, FVSI, and HLSI) values are calculated for the base case for all the lines of INSGS. 
4. A load bus (PQ Bus) is selected, and from the base case, its reactive power demand is gradually increased while keeping the loads on the other buses at the base load until the stability index value approaches equal one.

5. The value of the line stability index for each variation in the load is calculated.

6. The line with the greatest line stability index value is the most critical line of the bus.

7. Then another load bus (PQ bus) is selected, and steps 1-5 are repeated.

8. The maximum reactive power loading is extracted and is termed "the maximum load-ability" of the selected load bus obtained from step 4.

9. The voltage at the critical loading is obtained. It is known as the critical voltage of that particular load bus.

The maximum load-ability is ranked the highest implying the weakest bus in the system. It is a possible location of the UPFC device for voltage stability enhancement. Figure 3 shows the flow chart for calculating the voltage stability indices considered in this paper.

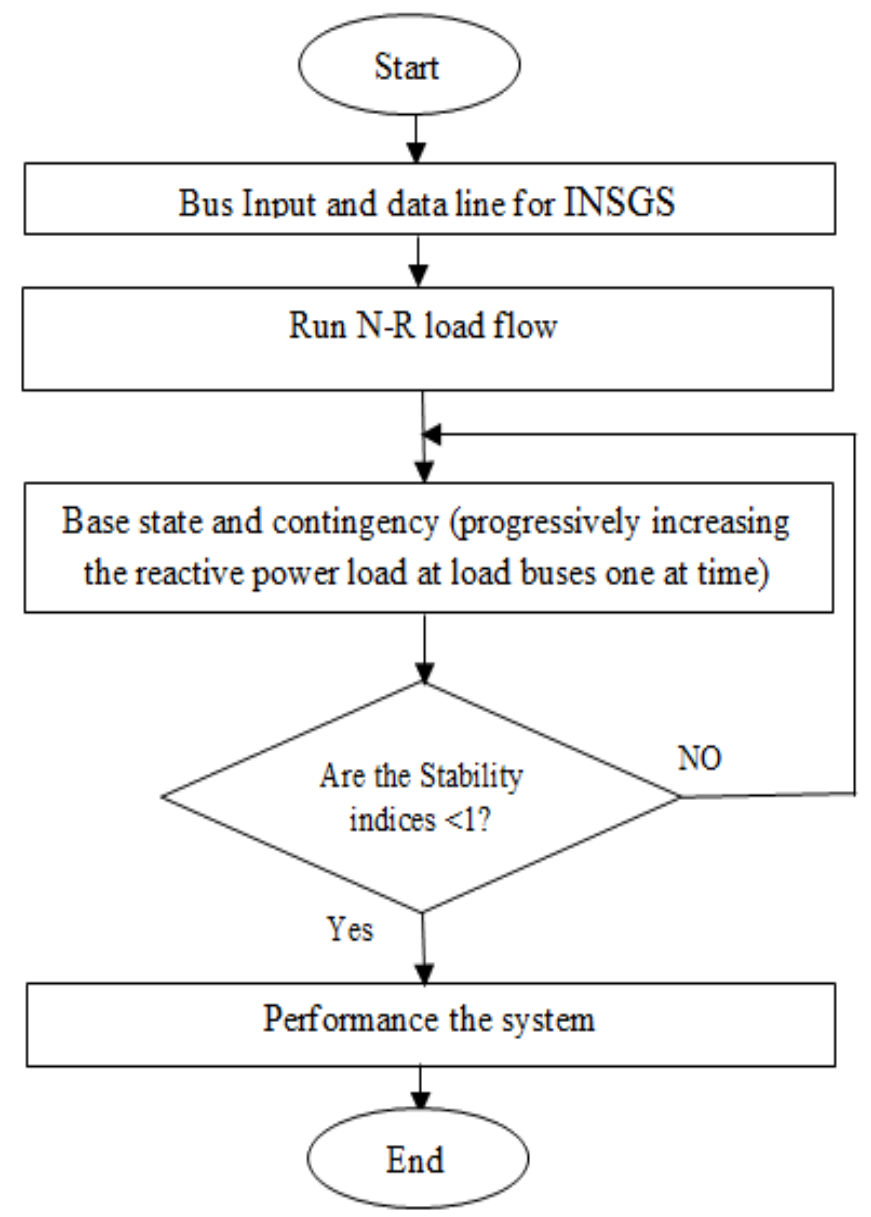

Figure 3: Flow chart of the calculating the voltage stability indicator

\section{RESULTS AND DISCUSSION}


HLSI mix two existing stability indicators the LSI and FVSI taking feature of the punctuality of LSI indicator and the constancy of FVSI indicator. In order to validate this HLSI, it was used with both the LSI \& the FVSI check the stability of the INSGS. The INSGS 24-bus has 11generator buses (PV), 13 load buses (PQ) and 39 interconnected lines or branches. Bus 1(MUSP) is selected as the slack bus , the bus data and line data are as shown in the appendix [12]. Figure 4 shows the single-line diagram of the system. The bus and line data used for the power flow analysis are as presented. The simulation result for both scenarios: the base state and the contingency are here discussed. Table 1 shows the base state values of the line stability indices and Figure 5 shows the bar charts of LSI, FVSI and HLSI against line Number. i.e. the thirty-nine (39) interconnected lines of the INSGS. At base state, the simulation was carried out to obtain the voltage stability indices: the LSI, FVSI and HLSI using equations 16, 19 and 20 respectively. From Table 1 and Figure 5, the system is stable as none of the indices of each line is near 1. It is observed that the three indices' values are almost equal. This validates the fact that the developed new index, HLSI can be used in place of the other two indices. 


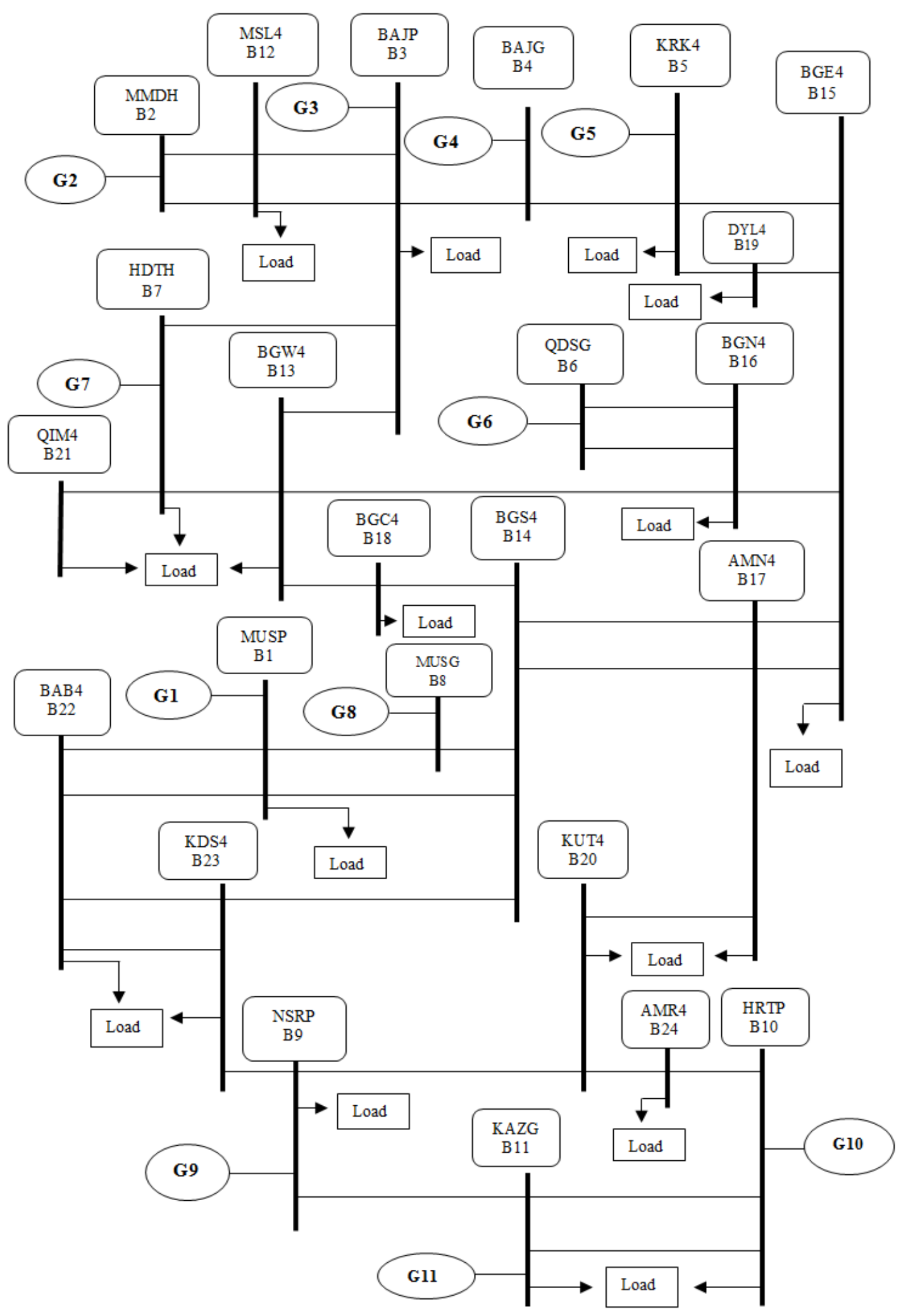

Figure 4: One line diagram of the INSGS $(400 \mathrm{kV})$ 
Table 1: Base case results for the (INSGS)

\begin{tabular}{|c|c|c|c|c|c|}
\hline \multirow[t]{2}{*}{ Line No. } & \multirow{2}{*}{$\begin{array}{c}\text { From } \\
\text { Bus }\end{array}$} & \multirow{2}{*}{$\begin{array}{c}\text { To } \\
\text { Bus }\end{array}$} & \multicolumn{3}{|c|}{ Voltage Stability Indices } \\
\hline & & & LSI & FVSI & HLSI \\
\hline 1 & 1 & 8 & 0.00616 & 0.00616 & 0.00616 \\
\hline 2 & 1 & 14 & 0.09961 & 0.09876 & 0.09876 \\
\hline 3 & 1 & 22 & 0.04690 & 0.04663 & 0.04663 \\
\hline 4 & 1 & 22 & 0.04690 & 0.04663 & 0.04663 \\
\hline 5 & 2 & 12 & 0.14045 & 0.13891 & 0.13891 \\
\hline 6 & 2 & 12 & 0.14045 & 0.13891 & 0.13891 \\
\hline 7 & 3 & 4 & 0.00046 & 0.00046 & 0.00046 \\
\hline 8 & 3 & 7 & 0.04458 & 0.04343 & 0.04458 \\
\hline 9 & 3 & 12 & 0.40092 & 0.40168 & 0.40168 \\
\hline 10 & 3 & 12 & 0.40092 & 0.40168 & 0.40168 \\
\hline 11 & 3 & 13 & 0.53707 & 0.51197 & 0.53707 \\
\hline 12 & 4 & 5 & 0.03365 & 0.03295 & 0.03295 \\
\hline 13 & 4 & 15 & 0.54646 & 0.53129 & 0.54646 \\
\hline 14 & 5 & 19 & 0.03248 & 0.03170 & 0.03248 \\
\hline 15 & 6 & 16 & 0.00766 & 0.00766 & 0.00766 \\
\hline 16 & 6 & 16 & 0.00766 & 0.00766 & 0.00766 \\
\hline 17 & 7 & 13 & 0.03355 & 0.03277 & 0.03277 \\
\hline 18 & 7 & 21 & 0.03625 & 0.03600 & 0.03600 \\
\hline 19 & 8 & 14 & 0.05424 & 0.05378 & 0.05378 \\
\hline 20 & 9 & 11 & 0.25455 & 0.24218 & 0.25455 \\
\hline 21 & 9 & 20 & 0.17212 & 0.16542 & 0.17212 \\
\hline 22 & 9 & 23 & 0.20304 & 0.20549 & 0.20304 \\
\hline 23 & 10 & 11 & 0.06586 & 0.06586 & 0.06586 \\
\hline 24 & 10 & 11 & 0.06586 & 0.06586 & 0.06586 \\
\hline 25 & 10 & 24 & 0.16822 & 0.16637 & 0.16637 \\
\hline 26 & 13 & 16 & 0.04765 & 0.04769 & 0.04769 \\
\hline 27 & 13 & 18 & 0.04114 & 0.04118 & 0.04118 \\
\hline 28 & 14 & 17 & 0.01634 & 0.01628 & 0.01628 \\
\hline 29 & 14 & 17 & 0.01634 & 0.01628 & 0.01628 \\
\hline 30 & 14 & 18 & 0.06194 & 0.06178 & 0.06178 \\
\hline 31 & 14 & 23 & 0.016550 & 0.16429 & 0.16429 \\
\hline 32 & 15 & 16 & 0.01455 & 0.01457 & 0.01457 \\
\hline 33 & 15 & 17 & 0.00881 & 0.00882 & 0.00882 \\
\hline 34 & 15 & 17 & 0.00881 & 0.00882 & 0.00882 \\
\hline 35 & 15 & 19 & 0.00665 & 0.00667 & 0.00667 \\
\hline 36 & 17 & 20 & 0.08971 & 0.08029 & 0.08971 \\
\hline 37 & 20 & 24 & 0.03680 & 0.03618 & 0.03680 \\
\hline 38 & 22 & 23 & 0.11273 & 0.11153 & 0.11153 \\
\hline 39 & 22 & 23 & 0.11273 & 0.11153 & 0.11153 \\
\hline
\end{tabular}




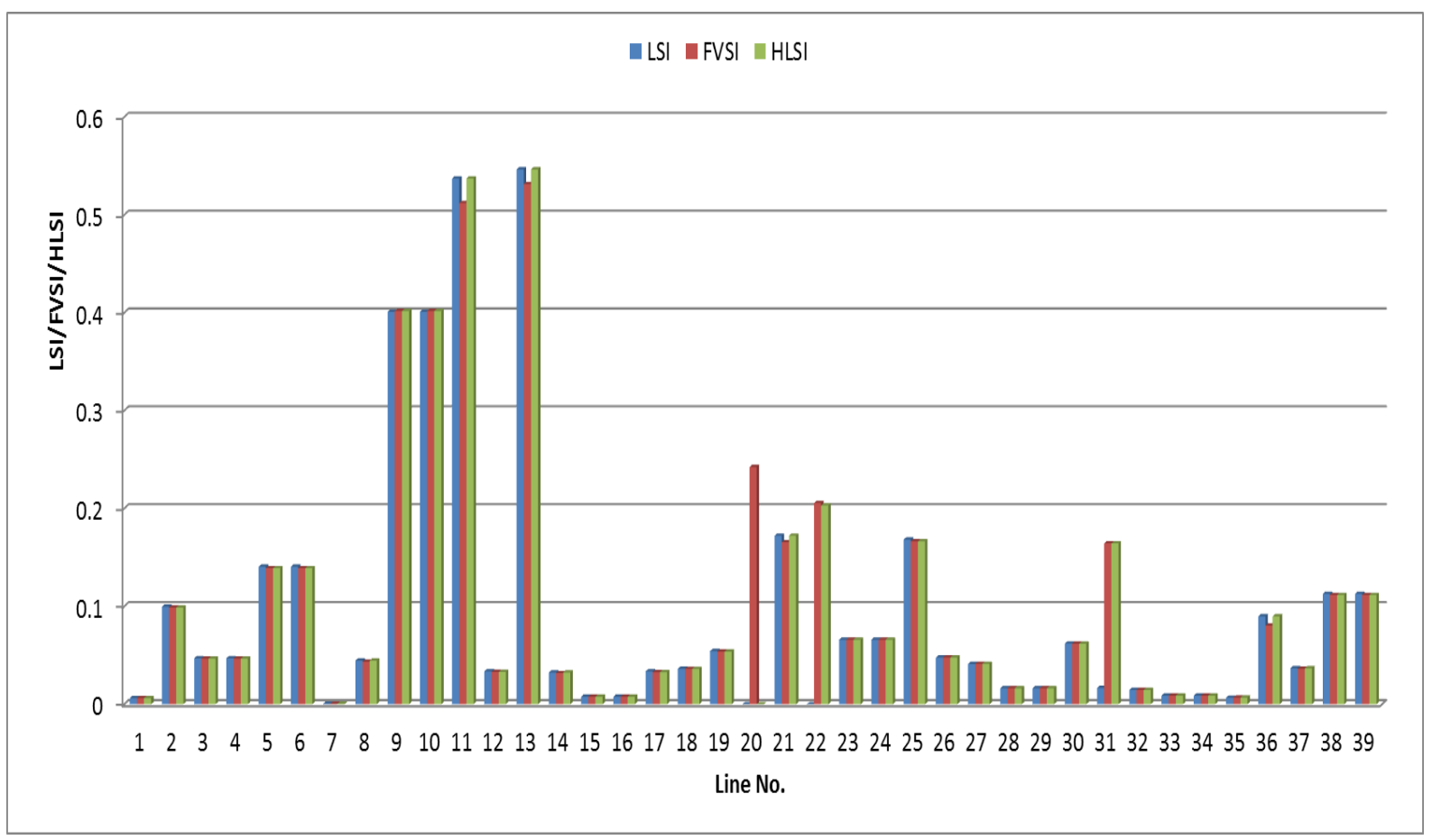

Figure 5: The LSI, FVSI and HLSI Vs Line No. for the Base state of the (INSGS)

The Simulation of a contingency state considered is the difference in the demand for reactive power. The reveals load bus 24 is the weakest and most vulnerable to the bus because it has the lowest maximum permissible reactive load of (490.371 Mvar) as shown in Figure 6. This bus has two connected lines and the line critical with respect to load bus 24 is the line 20-24. The means that any addition to the reactive load will cause the voltage collapse on the system. Bus 14 has the maximum load-ability and optional reactive load of around (4750 Mvar).

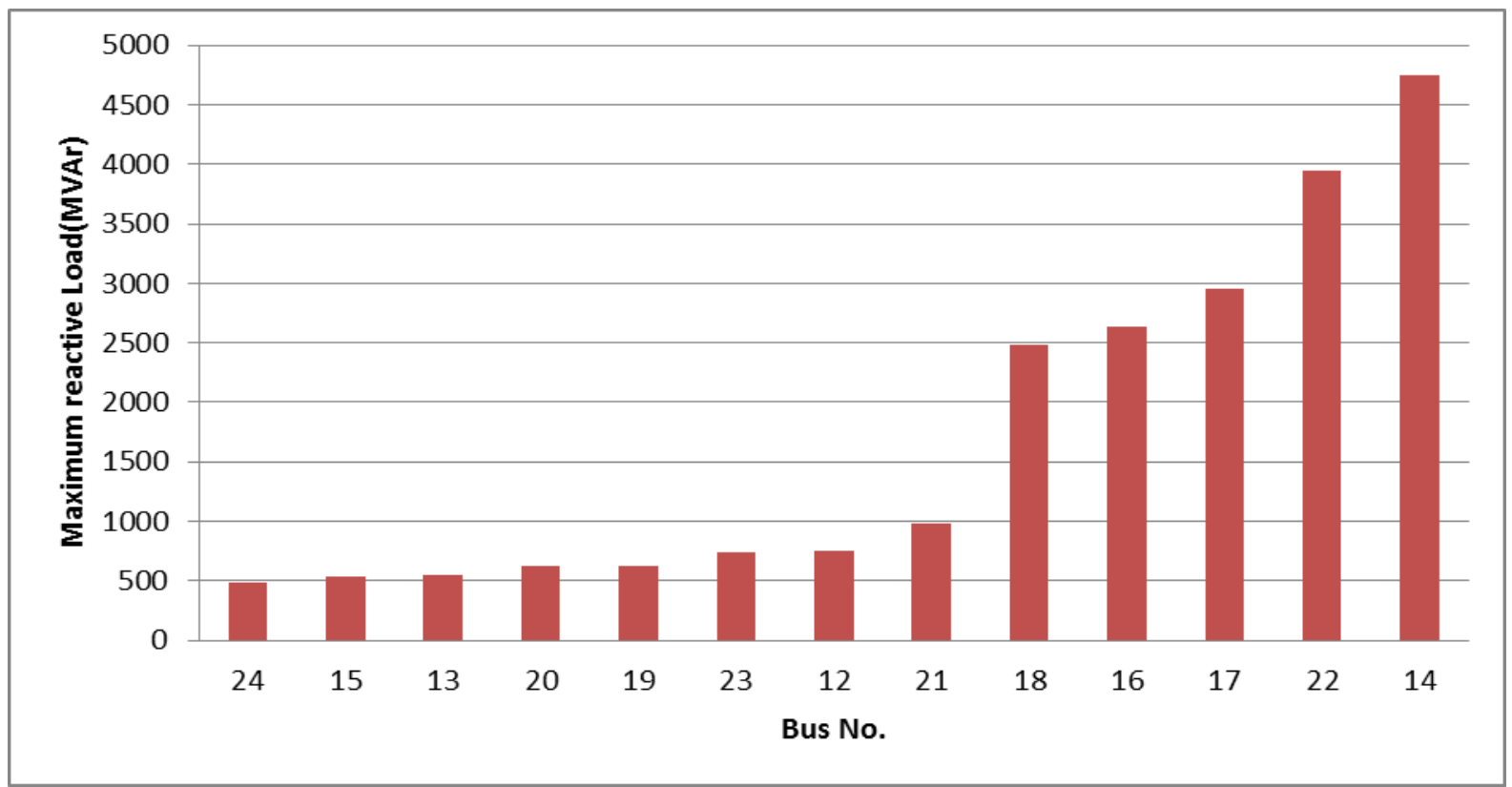

Figure 6: Maximum reactive loads (Q MVAr) at load buses of (INSGS) 
The power reactive variation on bus 24 was performed to investigate indicators with load reactive and voltage characteristics. The simulation results are as in Table 2 while Figure 7 presented the diagram of voltage magnitude and voltage stability indexes (LSI, FVSI, and HLSI) versus to Q (Mvar) variation for bus 24 It is worthy of note that the diagram of LSI \& HLSI coincide, this gives credence to the new index, HLSI also for determining the maximum load-ability of the load buses. This will consequently guide the operator to take quick action to avert the voltage collapse when a particular bus is being overloaded and where to place compensation devices is so revealed.

Table 2: Reactive power variations on load bus 24 (AMR4)

\begin{tabular}{|c|c|c|c|c|}
\hline \multirow[t]{2}{*}{ Q (Mvar) } & \multicolumn{4}{|c|}{ Bus $24-1^{\text {st }}$ weakest bus (20-24) } \\
\hline & $\begin{array}{l}\text { Vmag. } \\
\text { (p.u) }\end{array}$ & LSI & FVSI & HLSI \\
\hline 160.371 & 0.992 & 0.03680 & 0.03618 & 0.03680 \\
\hline 260.371 & 0.970 & 0.27304 & 0.27011 & 0.27011 \\
\hline 360.371 & 0.947 & 0.37778 & 0.37384 & 0.37384 \\
\hline 460.371 & 0.879 & 0.53450 & 0.52836 & 0.52836 \\
\hline 470.371 & 0.876 & 0.54609 & 0.53983 & 0.5398 \\
\hline 480.371 & 0.874 & 0.93066 & 0.95045 & 0.93066 \\
\hline 490.371 & 0.871 & 0.99197 & 0.97280 & 0.97280 \\
\hline
\end{tabular}

From Figure 7, for load bus 24, it is observed that the curve of the voltage magnitude drops as the reactive power is increased while the voltage stability indices value also increase until voltage collapse occurs. The HLSI, as could be seen, gives a true representation of the hybrid of LSI and the FVSI indices. This result for the 24-bus system validates the accuracy of the new hybrid line stability index (HLSI) as compared with the others found in the literature [13]. 


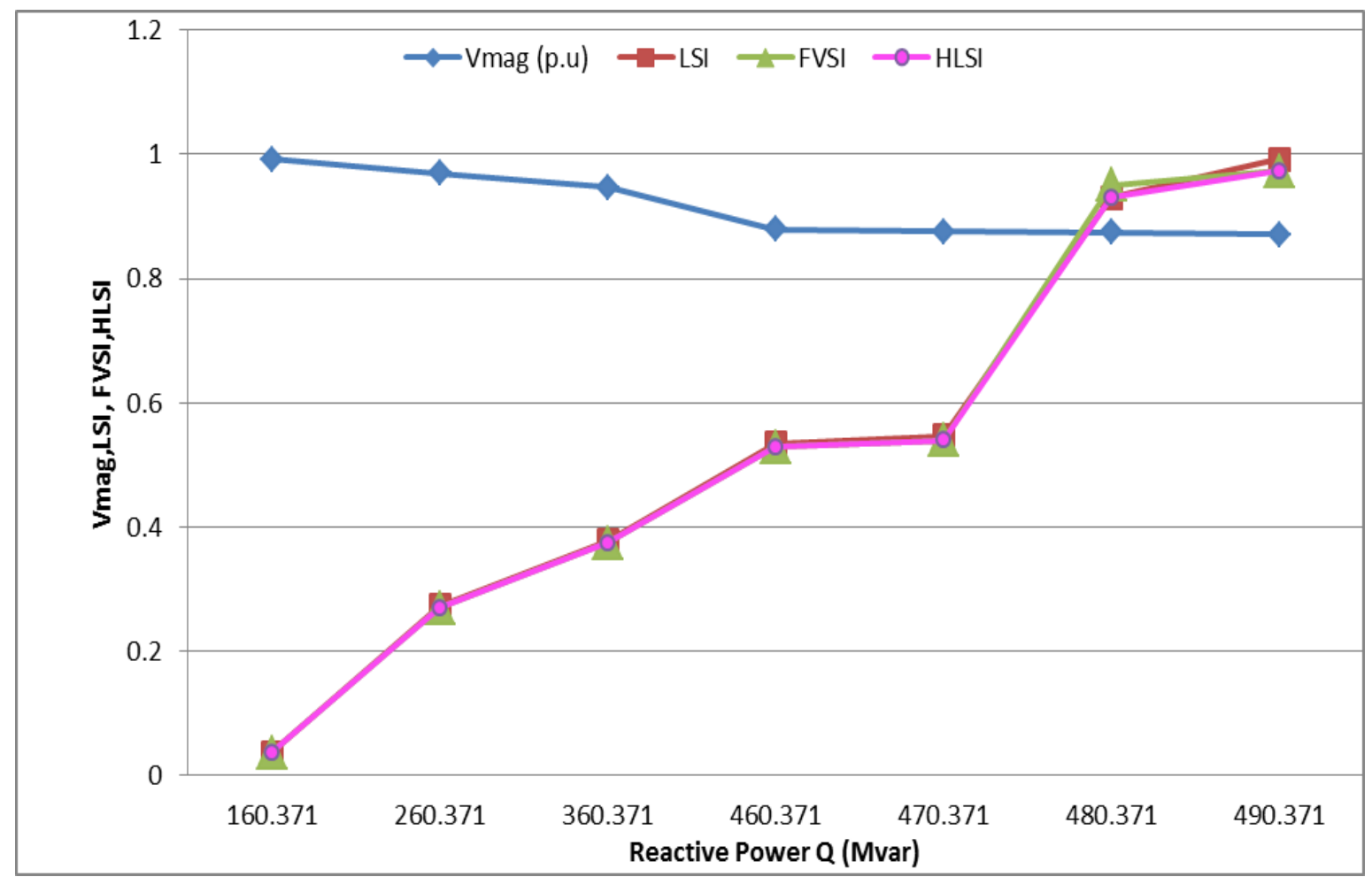

Figure 7: The load variation on Bus 24

The maximum load-ability of each load bus, the most critical line, and most stable line with respect to a particular load bus are identified and tabulated as shown in Table 3. The most stable lines are lines with the least voltage stability indices while the critical lines are the lines with the highest values of the voltage stability indices with respect to individual load buses. Table 3 shows the 24-bus system ranking of the load buses as the most stable and critical line as connected to each load buses.

Table 3: Load Bus Most Stable and Critical Line for 24-Bus

\begin{tabular}{|c|c|c|c|c|c|c|c|}
\hline $\begin{array}{c}\text { Bus } \\
\text { No. }\end{array}$ & $\begin{array}{c}\text { Bus } \\
\text { Name }\end{array}$ & $\begin{array}{c}\text { Max. Load } \\
\text { (MVAr) }\end{array}$ & $\begin{array}{c}\text { Most } \\
\text { Stable } \\
\text { line }\end{array}$ & HLSI & $\begin{array}{c}\text { Critical } \\
\text { line }\end{array}$ & HLSI & Ranking \\
\hline 24 & AMR4 & 490.371 & $10-24$ & 0.56279 & $20-24$ & 0.97280 & 1 \\
\hline 15 & BGE4 & 535.6579 & $15-19$ & 0.00674 & $5-15$ & 0.96403 & 2 \\
\hline 13 & BGW4 & 552.4481 & $13-18$ & 0.04222 & $3-13$ & 0.98077 & 3 \\
\hline 20 & KUT4 & 625.1756 & $17-20$ & 0.11156 & $9-20$ & 0.99419 & 4 \\
\hline 19 & DYL4 & 631.1712 & $15-19$ & 0.20401 & $5-19$ & 0.96394 & 5 \\
\hline 23 & KDS4 & 740.446 & $22-23$ & 0.55772 & $9-23$ & 0.99271 & 6 \\
\hline 12 & MSL4 & 752.4481 & $2-12$ & 0.34559 & $3-12$ & 0.99932 & 7 \\
\hline 21 & QIM4 & 979.3182 & Nil & Nil & $7-21$ & 0.99049 & 8 \\
\hline
\end{tabular}




\begin{tabular}{|c|c|c|c|c|c|c|c|}
\hline 18 & BGC4 & 2481.4688 & $13-18$ & 0.73979 & $14-18$ & 0.96360 & 9 \\
\hline 16 & BGN4 & 2639.1261 & $6-16$ & 0.16078 & $13-16$ & 0.98091 & 10 \\
\hline 17 & AMN4 & 2956.0014 & $15-17$ & 0.56929 & $14-17$ & 0.98764 & 11 \\
\hline 22 & BAB4 & 3944.6695 & $22-23$ & 0.14446 & $1-22$ & 0.99601 & 12 \\
\hline 14 & BGS4 & 4750 & $14-17$ & 0.22970 & $1-14$ & 0.9876 & 13 \\
\hline
\end{tabular}

\section{CONCLUSIONS}

The new line stability index (HLSI) combines two existing voltage stability indices: the LSI and FVSI taking advantage of the accuracy of the LSI index and the fastness of the FVSI index. In order to validate this new line stability index (HLSI), it was used together with the LSI and the FVSI to investigate the voltage stability of the 24-bus INSGS for two possible situations: the base state and the contingency analysis i.e. the variation of reactive load on load buses one at a time.

The simulations for the 24- bus INSGS revealed that for the base case, the system is stable because the three indices' values are approximately equal and are far less than one. For the contingency state, bus 24 was revealed to be the weakest bus as the indices' values are very close to one. This implies proximity to voltage collapse and it has the smallest maximum reactive loading of $490.371 \mathrm{Mvar}$. This means that bus 24 is the optimal location for placement of a FACTs device for improving the voltage profile at that bus as a measure against voltage collapse. Line 20-24 is the critical line of the system as the three stability indices' values of this line are very close to one and are almost equal. These results show that the new line stability index (HLSI) developed is valid and accurate since the result tallies with those obtained for the 24- bus INSGS in the technical literature [13].

\section{NOMENCLATURE}

$\mathrm{V}_{1}, \mathrm{~V}_{2} \quad$ Magnitude of voltage at sending and receiving end

$\mathrm{P}_{2}, \mathrm{Q}_{2} \quad$ Receiving end active and reactive power

$\mathrm{S}_{2} \quad$ Apparent power at receiving end

$\delta_{1}, \delta_{2} \quad$ Voltage angle at the sending and receiving end bus

$\mathrm{I}_{2} \quad$ Receiving end current of transmission line

$\mathrm{R}, \mathrm{X}, \theta$ Line resistance, reactance and impedance angle

$\mathrm{Z} \quad$ Line impedance amplitude

FVSI Fast voltage stability indices

HLSI Hybrid line stability index

LSI Line stability index 


\section{APPENDIX}

\section{SIMULATION PARAMETERS}

Bus Data

\begin{tabular}{cccccc}
\hline Bus No. & Bus Name & V $($ p.u $)$ & (MW) & (MVAR) & $(\mathrm{MW})$ \\
\hline 1 & MUSP & 1.04 & 1.997795 & 1.166333 & - \\
2 & MMDH & 1.02 & 0 & 0 & 690.0973 \\
3 & BAJP & 1.025 & 1.248622 & 0.922467 & 405.9923 \\
4 & BAJG & 1.025 & 0 & 0 & 590.458 \\
5 & KRK4 & 1.0217 & 1.298567 & 0.604896 & 239.8735 \\
6 & QDSG & 1.0075 & 0 & 0 & 735.3046 \\
7 & HDTH & 1.03 & 2.53054 & 0.75612 & 202.97 \\
8 & MUSG & 1.04 & 0 & 0 & 369.036 \\
9 & NSRP & 1.0197 & 4.228665 & 1.983219 & 774.976 \\
10 & HRTP & 1.015 & 1.548291 & 0.721171 & 332.1326 \\
11 & KAZG & 1.0096 & 5.660419 & 2.946579 & 207.5829 \\
12 & MSL4 & 1 & 6.492833 & 3.024481 & 0 \\
13 & BGW4 & 1 & 5.76031 & 3.024481 & 0 \\
14 & BGS4 & 1 & 0 & 0 & 0 \\
15 & BGE4 & 1 & 8.490627 & 2.946579 & 0 \\
16 & BGN4 & 1 & 4.128776 & 1.391261 & 0 \\
17 & AMN4 & 1 & 1.26564 & 0.560014 & 0 \\
18 & BGC4 & 1 & 0.499449 & 1.814688 & 0 \\
19 & DYL4 & 1 & 0.832415 & 0.211712 & 0 \\
20 & KUT4 & 1 & 2.597134 & 1.081756 & 0 \\
21 & QIM4 & 1 & 1.098787 & 0.393182 & 0 \\
22 & BAB4 & 1 & 3.079934 & 1.846695 & 0 \\
23 & KDS4 & 1 & 2.130981 & 1.514458 & 0 \\
24 & AMR4 & 1 & 2.110221 & 1.603709 & 0 \\
\hline
\end{tabular}

Line Data

\begin{tabular}{ccccccc}
\hline $\begin{array}{c}\text { From } \\
\text { Bus }\end{array}$ & To Bus & $\begin{array}{c}\text { Voltage } \\
\text { Rating } \\
(\mathrm{KV})\end{array}$ & $\begin{array}{c}\text { Frequency } \\
\text { Rating(Hz) }\end{array}$ & R (p.u) & X (p.u) & B (p.u) \\
\hline MUSP & MUSG & 400 & 50 & 0.000125 & 0.001043 & 0.032791 \\
MUSP & BGS4 & 400 & 50 & 0.00122 & 0.01015 & 0.31897 \\
MUSP & BAB4 & 400 & 50 & 0.00081 & 0.00673 & 0.21165 \\
MUSP & BAB4 & 400 & 50 & 0.00081 & 0.00673 & 0.21165 \\
MMDH & MSL4 & 400 & 50 & 0.00144 & 0.01177 & 0.36439 \\
MMDH & MSL4 & 400 & 50 & 0.00144 & 0.01177 & 0.36439 \\
BAJP & BAJG & 400 & 50 & 0.00002 & 0.0002 & 0.00584 \\
BAJP & HDTH & 400 & 50 & 0.00345 & 0.03132 & 0.92808 \\
BAJP & MSL4 & 400 & 50 & 0.0042 & 0.03437 & 1.06426 \\
BAJP & MSL4 & 400 & 50 & 0.0042 & 0.03437 & 1.06426 \\
BAJP & BGW4 & 400 & 50 & 0.00483 & 0.04393 & 1.30165 \\
BAJG & KRK4 & 400 & 50 & 0.0018 & 0.01635 & 0.48447 \\
KRK4 & BGE4 & 400 & 50 & 0.005114 & 0.046492 & 1.377532 \\
KRK4 & DYL4 & 400 & 50 & 0.004247 & 0.038612 & 1.144052 \\
QDSG & BGN4 & 400 & 50 & 0.00015 & 0.00138 & 0.04086 \\
QDSG & BGN4 & 400 & 50 & 0.00015 & 0.00138 & 0.04086 \\
HDTH & BGW4 & 400 & 50 & 0.00485 & 0.04405 & 1.30515 \\
HDTH & QIM4 & 400 & 50 & 0.00299 & 0.02391 & 0.74035
\end{tabular}




\begin{tabular}{lllcccc} 
MUSG & BGS4 & 400 & 50 & 0.001094 & 0.009106 & 0.286176 \\
NSRP & KAZG & 400 & 50 & 0.00439 & 0.03993 & 1.18316 \\
NSRP & KUT4 & 400 & 50 & 0.00432 & 0.03928 & 1.1639 \\
NSRP & KDS4 & 400 & 50 & 0.00383 & 0.03485 & 1.03256 \\
HRTP & KAZG & 400 & 50 & 0.00118 & 0.01076 & 0.3187 \\
HRTP & KAZG & 400 & 50 & 0.00118 & 0.01076 & 0.3187 \\
HRTP & AMR4 & 400 & 50 & 0.0029 & 0.0264 & 0.78216 \\
BGW4 & BGN4 & 400 & 50 & 0.00093 & 0.00847 & 0.25099 \\
BGW4 & BGC4 & 400 & 50 & 0.000616 & 0.005608 & 0.166179 \\
BGS4 & AMN4 & 400 & 50 & 0.00082 & 0.00749 & 0.22181 \\
BGS4 & AMN4 & 400 & 50 & 0.00082 & 0.00749 & 0.22181 \\
BGS4 & BGC4 & 400 & 50 & 0.000964 & 0.008772 & 0.259921 \\
BGS4 & KDS4 & 400 & 50 & 0.00308 & 0.02795 & 0.82827 \\
BGE4 & BGN4 & 400 & 50 & 0.00029 & 0.00262 & 0.07763 \\
BGE4 & AMN4 & 400 & 50 & 0.00043 & 0.00394 & 0.11674 \\
BGE4 & AMN4 & 400 & 50 & 0.00043 & 0.00394 & 0.11674 \\
BGE4 & DYL4 & 400 & 50 & 0.00087 & 0.00788 & 0.23348 \\
AMN4 & KUT4 & 400 & 50 & 0.02744 & 0.22904 & 0.09156 \\
KUT4 & AMR4 & 400 & 50 & 0.00479 & 0.04354 & 1.28998 \\
BAB4 & KDS4 & 400 & 50 & 0.00233 & 0.01935 & 0.60812 \\
BAB4 & KDS4 & 400 & 50 & 0.00233 & 0.01935 & 0.60812 \\
\hline
\end{tabular}




\section{REFERENCES}

[1] R. H. Al-Rubayi and H. A. Al-Baidhani, "Voltage Stability Study of the Iraqi Power Grid," Engineering and Technology Journal, vol. 30, pp. 312-324, 2012.

[2] I. Ibrahim, M. Nasser," Enhancement Voltage Stability of the Iraqi Power Grid Using Shunt FACTs Devices",Eng. \&Tech.Journal, Vol.34,Part (A), No.13,2016.

[3] R. H. Al-Rubayi and W. K. Al-Jubori, "An approach of voltage stability analysis for IEEE 9 bus system with UPFC," Advances in Natural and Applied Sciences, vol. 10, pp. 71-82, 2016.

[4] S. K. Sahu, S. S. Reddy, and S. J. Kumar, "New voltage stability index for voltage stability analysis in power system," Int. J. Elec. Electron. Eng. Res, vol. 2, pp. 13-20, 2012.

[5] J. Veleba and T. Nestorovic, "Performance of static voltage stability analysis in MATLAB environment with further applications," International Journal on Education and Information Technologies, vol. 7, pp. 133-145, 2013.

[6] P. Kundur, J. Paserba, V. Ajjarapu, G. Andersson, A. Bose, C. Canizares, et al., "Definition and classification of power system stability," IEEE transactions on Power Systems, vol. 19, pp. 13871401, 2004.

[7] Isaiah Adebayo, Yanxia Sun, "New Performance Indices for Voltage Stability Analysis in a Power System", Energies, 10, 2042,2017.

[8] S. do Nascimento and M. M. Gouvea Jr, "Voltage stability enhancement in power systems with automatic facts device allocation," Energy Procedia, vol. 107, pp. 60-67, 2017.

[9] F. M. Albatsh, S. Ahmad, S. Mekhilef, H. Mokhlis, and M. Hassan, "Optimal placement of unified power flow controllers to improve dynamic voltage stability using power system variable based voltage stability indices," PloS one, vol. 10, p. e0123802, 2015.

[10] M. Moghavvemi and F. Omar, "Technique for contingency monitoring and voltage collapse prediction," IEE Proceedings-Generation, Transmission and Distribution, vol. 145, pp. 634-640, 1998.

[11] I. Musirin and T. A. Rahman, "Novel fast voltage stability index (FVSI) for voltage stability analysis in power transmission system," in Student Conference on Research and Development, 2002, pp. 265-268.

[12] Iraqi National Control Center, Ministry of Electricity.

[13] R. H. Al-Rubayi and S. S. A. Alhalim, "Stability Improvement Of the (400kV) Iraqi Grid using the best FACTS Devices," Engineering and Technology Journal, vol. 33, pp. 1598-1618, 2015. 